\title{
Diabetes in rat pregnancy alters renal calcium and magnesium reabsorption and bone formation in adult offspring
}

Received: 14 December 2004 / Accepted: 23 February 2005 / Published online: 4 June 2005

C) Springer-Verlag 2005

\begin{abstract}
Aims/hypothesis: We tested the hypothesis that diabetes in pregnancy can result in the in-utero reprogramming of renal calcium and magnesium handling and of bone formation in the offspring, which persists into adulthood. Methods: Male offspring of streptozotocintreated diabetic rats (OD rats) and of control non-diabetic animals (OC rats) were investigated as neonates and at 8 , 12 and 16 weeks of age. Results: Compared with OC rats, urinary calcium and magnesium output was significantly reduced in OD rats at every age studied; $\mathrm{Na}^{+}$and $\mathrm{K}^{+}$outputs were unaffected. The renal expression of proteins involved in the tubular reabsorption of calcium (calcium ATPase, calbindin- $\mathrm{D}_{28 \mathrm{k}}$ and epithelial calcium channel) was increased in OD animals compared with that in OC animals. Additionally, we observed that adult OD rats had lower trabecular and higher cortical femoral bone volumes, explained by deposition of bone on the endosteal surface. Conclusions/interpretation: These data show that diabetes in pregnancy has profound effects on male offspring in
\end{abstract}

Unfortunately, H. O. Garland died before publication of this manuscript

H. Bond · J. D. Glazier · C. P. Sibley $(\bowtie)$

Academic Unit of Child Health, St Mary's Hospital,

University of Manchester,

Hathersage Road,

Manchester, M13 OJH, UK

e-mail: colin.sibley@man.ac.uk

Tel.: +44-161-2766484

Fax: +44-161-2241013

K. Hamilton

Department of Haematology, Guy's Hospital,

London, UK

R. J. Balment · H. O. Garland

School of Biological Sciences, University of Manchester,

Manchester, UK

J. Denton · A. J. Freemont

Department of Osteoarticular Pathology,

University of Manchester,

Manchester, UK terms of renal tubular calcium and magnesium reabsorption and the normal pattern of bone formation. These effects persist into adulthood. Such long-lasting effects of diabetes on kidney and the skeleton were not suspected and could have important implications for the health of children born to diabetic women.

Keywords Bone Calcium - Diabetes $\cdot$ Fetal origins · Magnesium · Placenta $\cdot$ Pregnancy $\cdot$ Renal $\cdot$ Skeleton

Abbreviations ECaC1: epithelial calcium channel 1 . OC: offspring of control pregnant mothers - OD: offspring of diabetic pregnant mothers PMCA: plasma membrane calcium ATPase

\section{Introduction}

Epidemiological and experimental evidence suggests that low birthweight predicts subsequent hypertension, hyperlipidaemia, insulin resistance, type 2 diabetes and ischaemic heart disease in adult life [1,2]. Disturbed glucose metabolism and gestational diabetes have also been observed in rat offspring born to diabetic mothers [3, 4]. However the substantial effect of maternal diabetes on electrolyte balance, and specifically calcium homeostasis has largely been ignored with respect to effects on the offspring.

Neonatal hypocalcaemia [5-8] and hypomagnesaemia $[6,9]$ are observed in infants born to diabetic mothers and have been associated with altered bone mineral content $[10$, 11]. Reduced bone mineral content and/or retarded skeletal development is found in the neonates of transgenic and streptozotocin-induced diabetic rats [12-15]. This may, in part, be related to the greatly increased renal calcium and magnesium loss suffered by the diabetic mother, as compared with her non-diabetic pregnant counterparts [16]; an effect that could influence fetal renal function. Active transcellular calcium transport in the kidney occurs mainly in the distal portion of the nephron [17] and involves three key proteins: epithelial calcium channel $1(\mathrm{ECaC} 1)$, cal- 
bindin- $\mathrm{D}_{28 \mathrm{~K}}$ and plasma membrane calcium ATPase (PMCA) [18-20]. Altered PMCA [20] and calbindin- $\mathrm{D}_{28 \mathrm{~K}}$ [21] expression has been observed in diabetic rats. No information is available regarding the effect of diabetes on $\mathrm{ECaCl}$ and no data are available on the effects of diabetic pregnancy on the expression of these calcium-transporting proteins in the resulting offspring.

The possibility that calcium or magnesium homeostasis may be altered in adult offspring of diabetic pregnancies has not previously been investigated. In this study we tested the hypothesis that offspring born to diabetic mothers exhibit alterations in bone formation and in renal calcium and magnesium reabsorption as a result of in-utero programming, which persist from birth through to adulthood.

\section{Materials and methods}

Diabetic and control pregnant rats

Female Sprague-Dawley rats (Charles River, Manston, Kent, UK) aged 8 weeks (weight 221-242 g) were rendered diabetic with streptozotocin (i. p. injection of $60 \mathrm{mg} /$ $\mathrm{kg} 0.1 \mathrm{~mol} / \mathrm{l}$ citrate buffer, $\mathrm{pH} 4.8$ ). Control rats were given an i. p. injection of the vehicle $(0.1 \mathrm{~mol} / \mathrm{l}$ citrate buffer $)$ alone. After $48 \mathrm{~h}$, diabetes was confirmed in the former group by the development of glycosuria (Uristix; Ames DVN, Miles, Slough, UK) and hyperglycaemia (blood glucose concentration $>15 \mathrm{mmol} / \mathrm{l}$ ). Blood for the latter was obtained via direct needle puncture of the tail vein, which was followed by immediate assay using a blood glucose analyser (Hemocue, Sheffield, UK). The diabetic female rats were then housed with a non-diabetic male for mating. The first day of gestation (term $=21-23$ days) was determined by the discovery of a copulation plug. The female was removed and housed individually. All mothers were provided with nesting material and allowed to litter naturally. All experiments were performed in accordance with the UK Animals (Scientific Procedures) Act of 1986.

\section{Offspring}

Neonatal study Urine samples were collected from offspring of diabetic pregnant mothers (OD rats) and offspring of control pregnant mothers (OC rats) on day 1 postpartum using the method previously described by Kavlock and Gray [22]. This method adopts the principle that neonatal rats do not micturate voluntarily, but require an external stimulus to empty their bladders. The three largest male OD and OC rats were removed from their mothers within 1 day postpartum and their bladders emptied via stimulation of the perineal region. The pups were then incubated at $37^{\circ} \mathrm{C}$ for $2 \mathrm{~h}$, the bladder emptied again, and the urine sample collected. Following determination of urine volume, the samples from the same litter were pooled to produce a sufficient volume for analysis.
Terminal carotid blood samples were then collected for analysis, and the animals were killed by cervical dislocation. Blood was collected into heparinised tubes and centrifuged immediately to separate the plasma. Both kidneys were removed, immediately frozen in liquid nitrogen, and stored at $-80^{\circ} \mathrm{C}$ until analysis. Hind legs were removed and stored in $100 \%$ ethanol until analysis.

Adult study Immediately following birth, all offspring were cross-fostered. For this purpose, pups were sexed and litters limited to six male pups. One-half of the control mothers had their pups removed. The other half of the control mothers then had their offspring (OC rats) removed and fostered onto this initial group of control mothers. The OD pups were then removed from their diabetic mothers and fostered onto the remaining group of control mothers. All mothers and pups were left undisturbed for 3 weeks. After 3 weeks, the pups were weaned, housed in groups of 3-4 and given free access to food and water.

\section{Metabolism studies}

Metabolism studies were performed on OD and OC rats housed individually in wire-bottomed Metabowl cages (Astra-Zeneca, Loughborough, UK) at 8, 12 and 16 weeks. Animals were acclimated to the cages for a period of 7 days. Collections were made every $24 \mathrm{~h}$ over a 3-day period, noting food and fluid intake and output of urine and faeces. Urine samples were kept at $4^{\circ} \mathrm{C}$ until further analysis. After a period of at least 1 day following the metabolic study, one animal from each litter was killed by cervical dislocation. Following immediate laparotomy, a blood sample was withdrawn from the abdominal aorta into a heparinised tube for plasma separation. Both kidneys were removed and immediately frozen in liquid $\mathrm{N}_{2}$. Femurs were also removed, the bone stripped, and stored in $100 \%$ ethanol until analysis. Other animals were returned to their normal cages between metabolic studies.

\section{Analyses}

Urinary $\mathrm{Na}^{+}$and $\mathrm{K}^{+}$concentrations were analysed in duplicate using flame photometry (Corning 480 Photometer; Corning, Halstead, Essex, UK) standardised for urine $(160 \mathrm{mmol} / \mathrm{l} \mathrm{NaCl}, 80 \mathrm{mmol} / \mathrm{l} \mathrm{KCl})$ with combined Corning MultiCal vials. Urinary and plasma calcium and magnesium concentrations were analysed in triplicate by flame atomic absorption spectrophotometry (Perkin Elmer 3100 Spectrophotometer; Seer Green, Buckinghamshire, UK). Samples for calcium analysis were diluted $1: 50$ in a $0.3 \%$ lanthanum $\left(\mathrm{LaCl}_{3} \cdot \mathrm{H}_{2} \mathrm{O}\right)$ solution. Samples were diluted in deionised water for magnesium analysis (urine 1:200, plasma 1:50).

Samples were assayed for plasma glucose concentration by the glucose oxidase-peroxidase method (Ames SeraPak; Bayer Diagnostics, Basingstoke, Hampshire, UK). 
Western blotting

Protein samples were prepared from either one adult kidney from each animal or from pooled kidneys of neonates from the same mother to obtain sufficient protein for analysis. The adult kidneys were taken from animals aged 8-12 weeks (the effects of diabetes were similar across this age range-see Results). Kidneys were thawed and homogenised in buffer containing $12 \mathrm{mmol} / 1$ HEPES ( $\mathrm{pH} 7.6)$, $300 \mathrm{mmol} / 1 \mathrm{mannitol}, 2 \mu \mathrm{g} / \mathrm{ml}$ pepstatin, $1 \mu \mathrm{g} / \mathrm{ml}$ leupeptin and $100 \mu \mathrm{mol} / 1$ AEBSF [4-(2-aminoethyl)benzenesulphonyl fluoride]. The homogenate was centrifuged at 2,500 $\mathrm{g}$ for $15 \mathrm{~min}$, and aliquots of this post-nuclear supernatant stored at $-80^{\circ} \mathrm{C}$ for calbindin- $\mathrm{D}_{28 \mathrm{~K}}$ assay. The remaining supernatant was centrifuged at $100000 \mathrm{~g}$ for $30 \mathrm{~min}$ to obtain a particulate protein pellet. This was resuspended in buffer (as above), and aliquots were stored at $-80^{\circ} \mathrm{C}$ for $\mathrm{ECaC} 1$ and PMCA assay. Samples were normalised for protein content (Bio-Rad Protein Assay, BioRad Laboratories, Hemel Hempstead, Hertfordshire, UK). A pooled adult kidney protein sample was run on every blot to allow normalisation of density data between different blots.

Protein-SDS complexes were prepared by adding a $15-\mu \mathrm{l}$ sample of kidney protein to $7.5 \mu \mathrm{l}$ reducing buffer $(8 \mathrm{~mol} / \mathrm{l}$ urea, 5\% SDS, 0.04\% bromophenol blue, $455 \mathrm{mmol} / 1 \mathrm{di}-$ thiothreitol in $50 \mathrm{mmol} / \mathrm{l}$ Tris- $\mathrm{HCl}, \mathrm{pH}$ 6.9). Samples were subjected to SDS-PAGE on a 7, 10 and $12 \%$ gel for PMCA (15- $\mu \mathrm{g}$ protein), $\mathrm{ECaC} 1$ (30 $\mu \mathrm{g}$ neonate protein, $50 \mu \mathrm{g}$ adult protein) and calbindin- $\mathrm{D}_{28 \mathrm{~K}}(15 \mu \mathrm{g}$ protein), respectively, and then electrotransferred onto nitrocellulose membranes (Amersham Pharmacia Biotech, Little Chalfont, UK). The antisera used were mouse monoclonal anti-calbindin- $\mathrm{D}_{28 \mathrm{~K}}$ (1:2,500 dilution; Sigma, Poole, Dorset, UK), mouse monoclonal anti-PMCA 5F10 (1:1,500 dilution; Cambridge Bioscience, Cambridge, UK) and affinity-purified rabbit polyclonal anti-ECaC1 (1:1,000 dilution; Alpha Diagnostic International, San Antonio, TX, USA). Negative controls were performed by omitting the primary antibody. Immunoreactive species were detected with sheep anti-mouse antibody (1:1,000 dilution, Amersham Pharmacia Biotech) or goat anti-rabbit antibody (1:2,000 dilution, Dako, Ely, Cambridgeshire, UK) using an enhanced chemiluminescence detection system (ECL; Amersham Pharmacia Biotech). The density of the immunoreactive species was assessed following scanning of the film using a Quantinet 600 semiautomated image analyser (Leica Microsystems Cambridge, Cambridge, UK) and normalised to that of the control band for each experimental run.
Fig. 1 Urinary calcium output from neonates (a) and 8-, 12and 16-week-old OC rats (white bars) and OD rats (black bars) (b). Urinary magnesium output from neonates (c) and 8-, 12and 16-week-old OC rats (white bars) and OD rats (black bars) (d). The data shown are the means + SEM for six litters for all age groups. ${ }^{*} p<0.05, * * p<0.01$ vs OC a

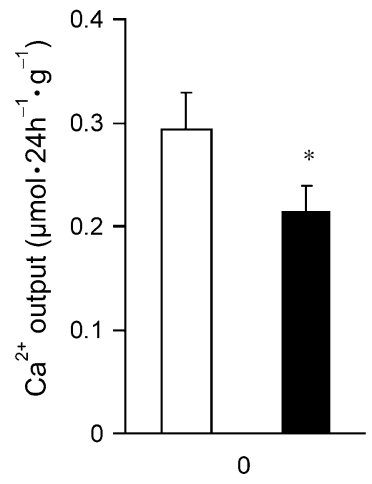

Age (weeks)

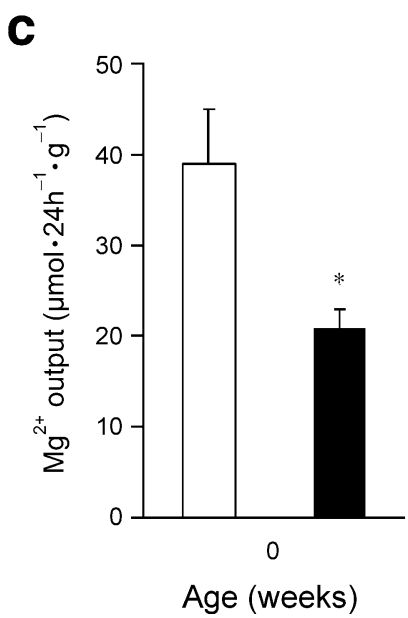

b

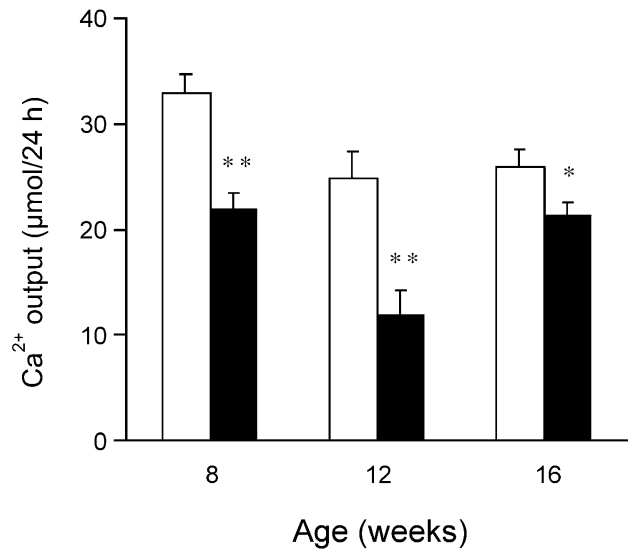

d

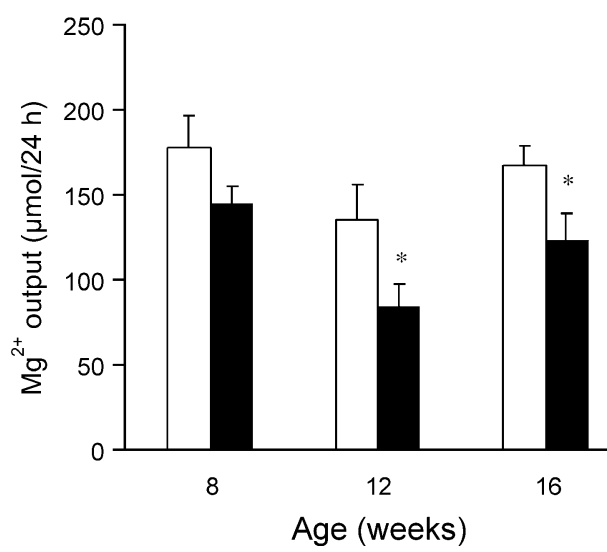


Bone analysis

This part of the study was carried out on distal adult (8-12 weeks of age) femurs and proximal neonatal tibias. These bones were selected because they could be guaranteed to be accurately oriented in the different age groups. Bone histomorphometry was performed on paired femurs and tibias from three adult and three neonatal animals. There was a straight-line relationship between the trabecular bone volumes of the two bones (data not shown). In the main part of the study, six adult femurs and six neonatal tibias from animals in each of the two groups were transected transversely through the mid-shaft. Each half of the bone was fixed in alcohol. The distal femur and proximal tibia were processed undecalcified into methylmethacrylatebased resin. The bones were supported during resin polymerisation in such a way that it was possible to make accurate coronal sections of each bone. Serial 7- $\mu \mathrm{m}$ tissue sections were stained with toluidine blue and von Kossa's stains, and then mounted on microscope slides. For each animal, one section of every five was taken, such that five sections were used for examination that covered about $150 \mu \mathrm{m}$ of bone. Sections were examined at $\times 60$ magnification. An area of bone extending from the primary bone of the growth plate to a fixed point in the diaphysis was used for the blinded assessment of cortical and trabecular bone volume, using a Quantinet 600 semiautomated image analyser. All parameters, their measurement and nomenclature are in accordance with internationally accepted standards [23]. The other part of each bone was embedded in methacrylate resin, with the shaft pointing upwards. The shaft was measured under a dissecting microscope attached to the image analyser. The internal and external diameters of the cortex, together with the absolute area of the cortex and its mean thickness, were measured.

Because of the large differences in absolute and derived proportional measurements of bone parameters between adult and neonatal animals, all data are expressed relative to the mean value for control (OC) bone $(100 \%)$.

\section{Statistical analysis}

Data are shown as means \pm SEM (where $n=$ the number of litters); where more than one offspring was studied from a particular litter, data were averaged to give a single value for that litter. Data from the two different groups were compared using Student's $t$-test.
Fig. 2 Expression of renal plasma membrane calcium ATPase (a, d), calbindin- $\mathrm{D}_{28 \mathrm{k}}$ $(\mathbf{b}, \mathbf{e})$ and $\mathrm{ECaCl}(\mathbf{c}, \mathbf{f})$ in neonatal $(\mathbf{a}-\mathbf{c})$ and adult $(8-12$ weeks old) (d-f) OD rats (black bars) and $\mathrm{OC}$ rats (white bars). Western blots were probed with specific antisera, as described in Materials and methods. The graphs show the optical density of the band corresponding to the protein of interest, quantified as a percentage of the positive control. The data shown are the means + SEM for six litters. $* p<0.05, * * p<0.01, * * * p<0.001$ vs OC
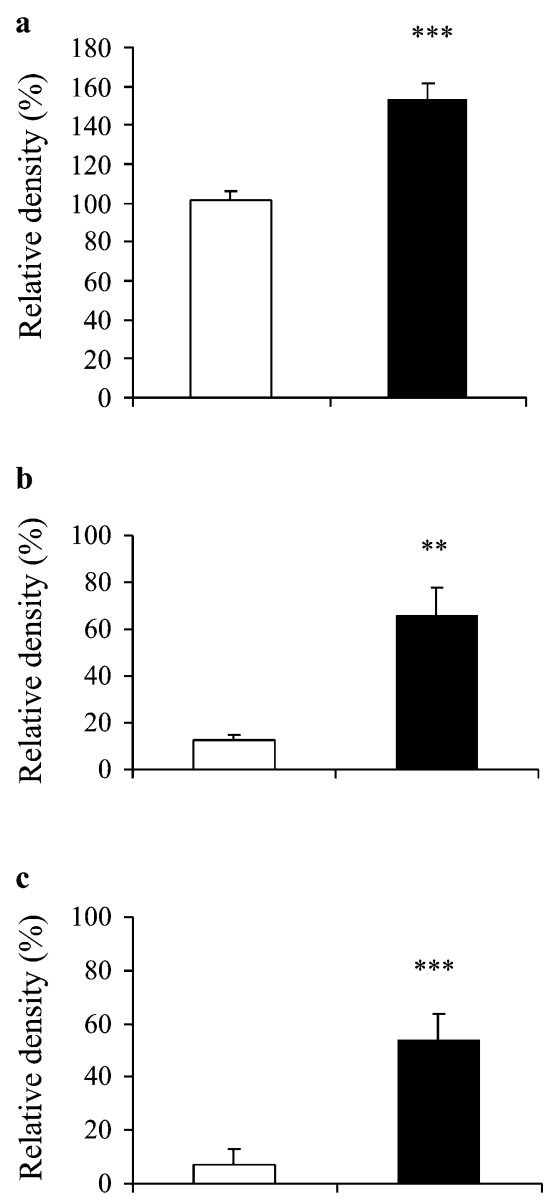

d
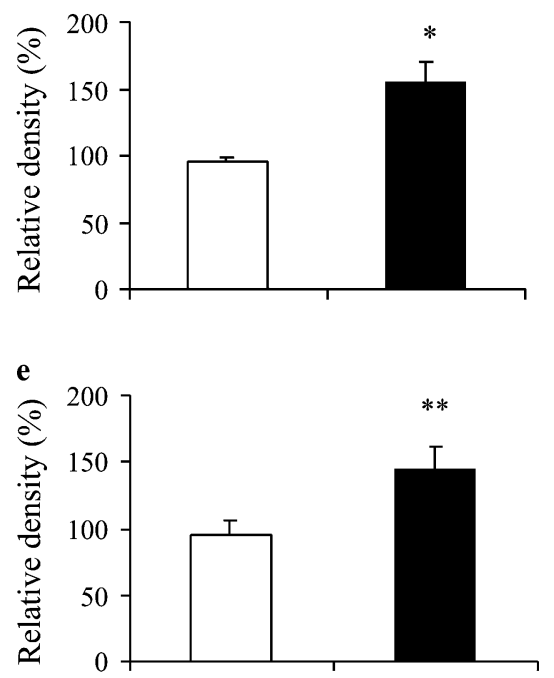

f

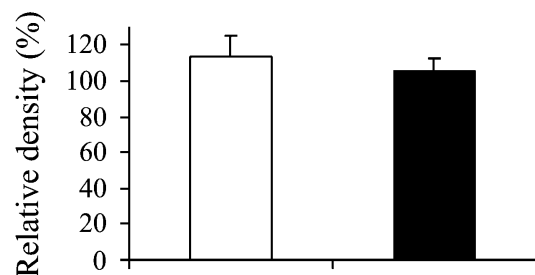




\section{Results}

Body weight, food consumption and fluid intake

At birth, the neonatal male OD rats were significantly lighter than the male OC rats $(5.1 \pm 0.2$ vs $6.2 \pm 0.2 \mathrm{~g}, p<0.001)$; thus, all neonatal urinary output data are expressed per gram body weight. No significant differences were observed between the two groups in terms of body weight, or food or fluid intake at 8,12 or 16 weeks (data not shown).

\section{Renal function}

There were no significant differences between the OD and OC rats in terms of urinary volume, osmolality, $\mathrm{Na}^{+}$or $\mathrm{K}^{+}$ output over $24 \mathrm{~h}$, or in plasma calcium or glucose concentrations at any of the time points studied (data not shown). In contrast, Fig. 1a shows that urinary calcium output was significantly lower in the OD rats than in the $\mathrm{OC}$ rats at 0 (neonates), 8, 12 and 16 weeks. Figure $1 \mathrm{~b}$ shows that compared with the $\mathrm{OC}$ rats, the OD rats had a significantly lower urinary magnesium output at 0 (neonates), 12 and 16 weeks.

\section{Western blotting}

Expression of PMCA The monoclonal anti-PMCA antibody detected a broad protein band at around $140 \mathrm{kDa}$
( 133-147 kDa) and a smaller band at $92 \mathrm{kDa}$, consistent with previous observations [19]; these bands were absent from negative control blots (data not shown). The relative density of the major immunoreactive species at $\sim 140 \mathrm{kDa}$, representing PMCA [19], was significantly greater in the OD rats than in the OC rats, in both neonatal (Fig. 2a) and adult (Fig. 2d) kidney membrane fractions.

Expression of calbindin- $D_{28 K}$ The monoclonal anticalbindin- $\mathrm{D}_{28 \mathrm{~K}}$ antibody detected a single protein band at $28 \mathrm{kDa}$ in the renal post-nuclear supernatant. The relative density of this band was significantly increased in both neonatal (Fig. 2b) and adult (Fig. 2e) OD rats as compared with that in $\mathrm{OC}$ rats.

Expression of ECaC1 The polyclonal anti-ECaC1 antibody detected a single protein band at $84 \mathrm{kDa}$ in membrane fractions of kidneys. The relative density of this band was significantly increased in the neonatal OD rats as compared with that in the neonatal OC rats (Fig. 2c); there was no difference between the two groups of adult rats (Fig. 2f).

\section{Bone analysis}

In neonatal tibias, there was no difference in trabecular bone volume between the two groups, although there was a slight increase in cortical bone volume in the OD rats relative to the $\mathrm{OC}$ rats (Fig. 3 ). In adult OD rats, there was a
Fig. 3 Adult (8-12 weeks old) femoral $(\mathbf{a}, \mathbf{b})$ and neonatal tibial $(\mathbf{c}, \mathbf{d})$ cortical $(\mathbf{a}, \mathbf{c})$ and trabecular (b, d) bone volume in $\mathrm{OD}$ rats (black bars) and $\mathrm{OC}$ rats (white bars). The data are expressed relative to the mean value for OC bone $(100 \%)$ and are the means + SEM for six litters. ${ }^{*} p<0.05, * * p<0.01$ OD vs OC

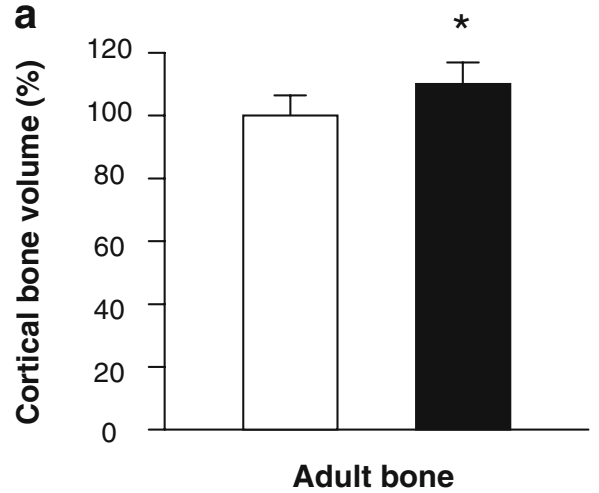

b

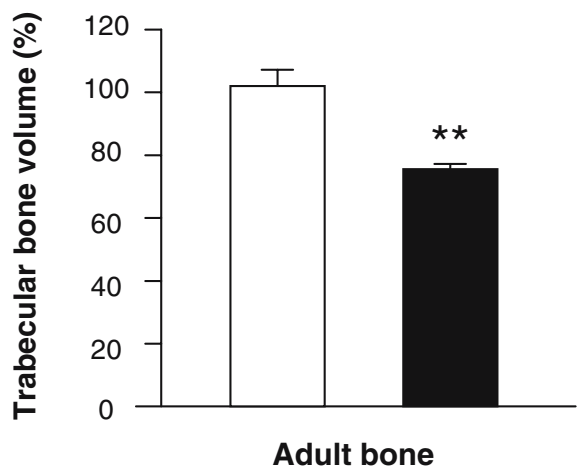

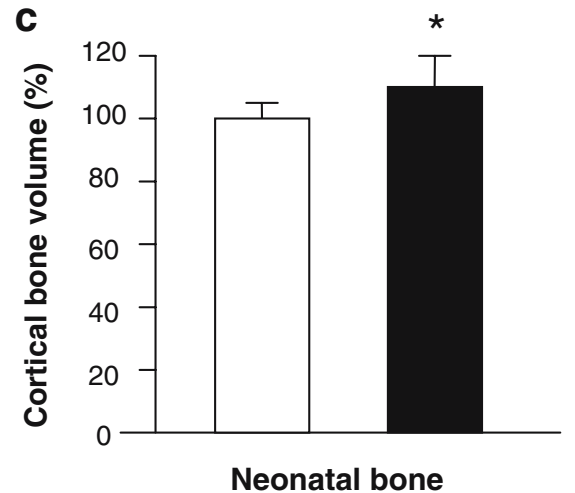

d

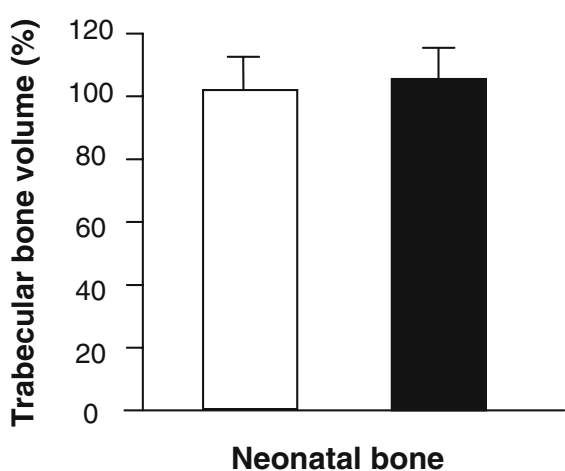


Fig. 4 Representative sections of adult (8-12 weeks old) femurs from OC (a) and OD (b) rats. Note the thickened cortex in the section from the OD animal. Bar graphs of bone parameters in the two groups of rats $(\mathbf{c}-\mathbf{f})$. External (c) and internal (d) diameters, mean thickness (e), and area (f) of the cortexin adult (8-12 weeks old) femurs from OC rats (white bars) and OD rats (black bars). The data are expressed relative to the mean value for $\mathrm{OC}$ bone $(100 \%)$ and are the means + SEM, for six litters. ${ }^{*} p<0.05$, $* * p<0.01$ vs OC
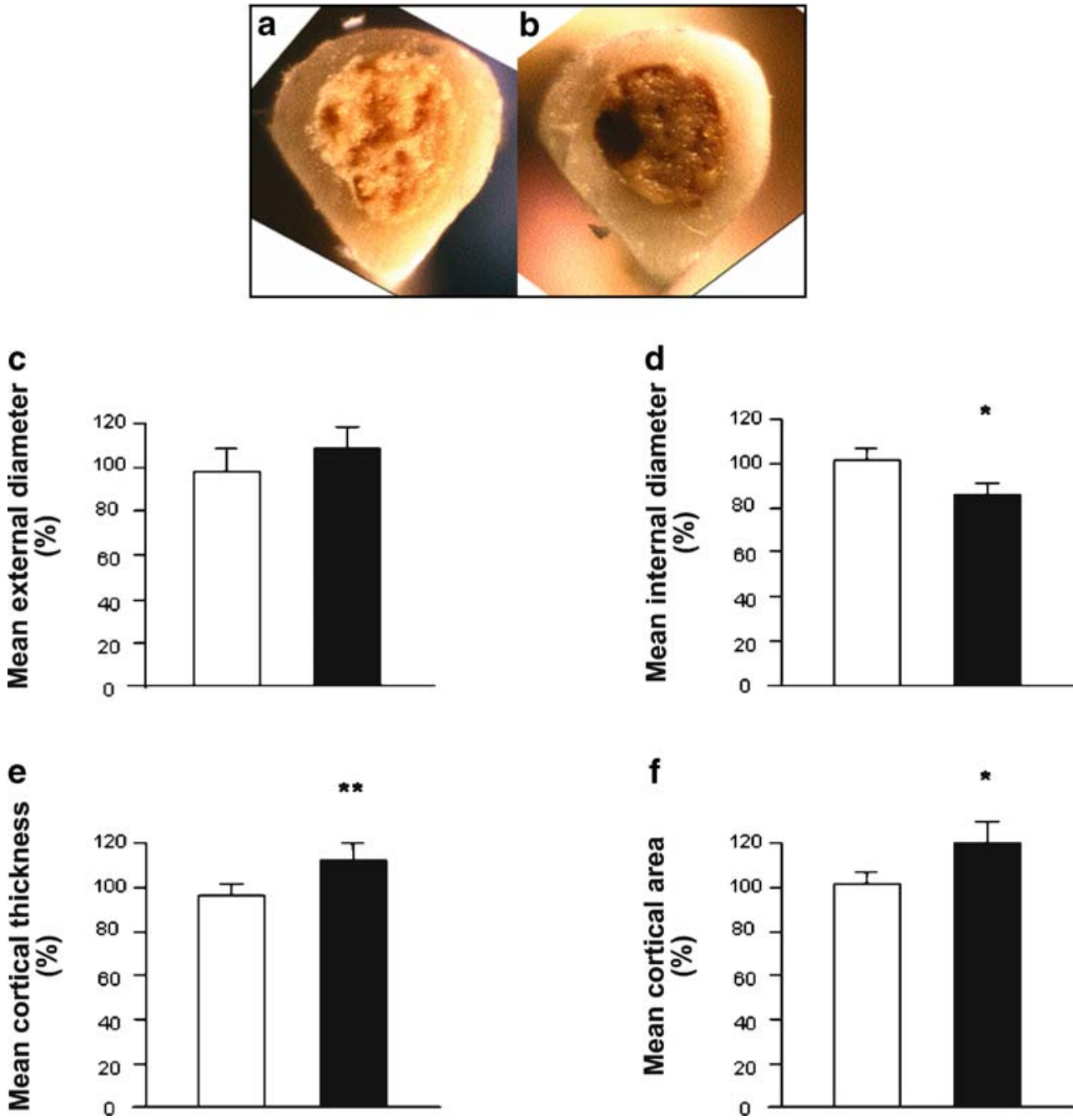

relative increase in cortical bone volume and a marked decrease in trabecular bone volume (Fig. 3). Further analysis of the adult bones revealed that the mean cortical area and thickness of the OD femurs were increased relative to those of the OC femurs, predominantly due to a decrease in mean internal diameter (Fig. 4).

\section{Discussion}

Diabetes mellitus in human pregnancy is associated with a number of abnormalities of calcium and magnesium homeostasis in the neonate including hypocalcaemia, hypomagnesaemia and altered bone mineral content [5-11]. The diabetic pregnant rat exhibits marked hypercalciuria and hypermagnesiuria [16, 24], and the newborn offspring have retarded ossification and delayed bone maturation [15, 24]. Despite these well-documented effects of diabetic pregnancy on calcium and magnesium homeostasis in the human and rat neonate, no previous study had investigated whether these effects persist beyond the neonatal period. Our results show that there are long-lasting effects on renal handling of calcium and magnesium and on the structure of bone.

Urinary calcium output was significantly reduced in OD animals compared with that in OC animals, in neonates and at all adult stages studied (up to 16 weeks of age). A similar decrease in urinary magnesium output was observed in OD animals. These changes occurred in the absence of any differences in food or water intake, or in plasma concentrations of glucose or calcium, and are the converse of those found in the diabetic mothers, where urinary calcium and magnesium output is specifically increased $[16,25]$. However, the changes in urinary calcium and magnesium output in diabetic mothers and their offspring occur in the absence of any change in urinary $\mathrm{Na}^{+}$or $\mathrm{K}^{+}$excretion. This indicates that the effect of diabetes on renal electrolyte reabsorption appears to involve a specific effect on the tubular handling of the divalent cations. We only investigated male offspring in the present study, and the effects of diabetic pregnancy on renal electrolyte excretion by female offspring also need to be considered; our preliminary data suggest that the effect is similar (H. Bond and K. Hamilton, unpublished observations). 
We next investigated the mechanism underlying the hypocalciuria in the OD neonates and adults by assessing the expression of renal proteins involved in tubular calcium reabsorption. Levels of calbindin- $\mathrm{D}_{28 \mathrm{~K}}$ and PMCA, as determined by western blotting, were higher in neonatal and adult OD animals than in OC animals. Levels of $\mathrm{ECaC} 1$ were also significantly higher in OD neonates, but this trend did not continue into adulthood. These three proteins are the primary proteins responsible for the transcellular transport/reabsorption of calcium from the renal tubule lumen back into the blood. Therefore, the observed increase in levels of PMCA, calbindin- $\mathrm{D}_{28 \mathrm{~K}}$ and $\mathrm{ECaC} 1$ (neonates only), if reflected in transport activity, would increase calcium reabsorption in the distal nephron [25, 26]. This suggests that the hypocalciuria observed in OD rats arises from tubular modification of calcium handling; a conclusion supported by our preliminary data showing that the renal fractional excretion of calcium is decreased in adult anaesthetised OD rats [27]. As OD pups were crossfostered onto control mothers at birth, factors within the in utero environment must have programmed the apparently permanent changes in calbindin- $\mathrm{D}_{28 \mathrm{k}}$ and PMCA expression and the more transient change in $\mathrm{ECaC} 1$ levels.

In contrast to their offspring, diabetic pregnant rats show marked hypercalciuria and hypermagnesiuria [16]. However, glucose could be responsible for the altered renal divalent cation handling in both diabetic mothers and their offspring. Glucose rapidly crosses the placenta down a maternofetal plasma concentration gradient; consequently, and fetuses of diabetic rats show a similar degree of hyperglycaemia as their mothers [28]. If high plasma or tubular glucose inhibits calcium reabsorption in early parts of the nephron, the response in both mother and fetus may be to increase distal tubular PMCA and calbindin- $\mathrm{D}_{28 \mathrm{k}}$ expression, as we have shown previously in mothers [21]. If such a response in the fetal kidney in utero persisted in the normoglycaemic offspring ex utero, hypocalciuria would develop. This reasoning is consistent with the results of the present study.

We have previously shown that unidirectional calcium transport across the placenta of the diabetic pregnant rat is impaired [29] and that OD fetuses in utero are calcium deficient [29]. This could exacerbate the glucose effect described above, fetal calcium deficiency resulting in decreased tubular concentrations of calcium and, in turn, the upregulation of the calcium-transporting proteins. The hypothesis that fetal kidney expression of calcium-transporting proteins is permanently programmed by prevailing in-utero glucose and/or calcium concentrations should be tested in future experiments. Such experiments also need to examine related endocrine changes: in a separate study we have found that concentrations of serum parathyroid hormone $(\mathrm{PTH})$ are reduced in 8-week-old OD rats relative to those in OC rats [30].

The previously reported abnormal skeleton formation and bone mineral content in neonates of diabetic rats [1215] led us to examine the distribution of bone between trabecular and cortical compartments in neonatal and adult offspring. In adult OD rats there was a marked shift from trabecular to cortical compartments. Measurements of shaft diameter and the proportion and distribution of cortical bone in adults showed that the thickening of the cortex was explained by the accumulation of bone on the endosteal (inner) surface. The mechanism underlying this effect now requires investigation, but must have its origins in utero. It could be a primary effect of maternal diabetes on fetal bone cell function (e.g. due to the programming of mechanisms leading to endocortical bone apposition) or a secondary effect of maternal diabetes on offspring renal function that involves the accumulation of minerals reabsorbed in the kidney postnatally at the endosteal site. Importantly, we have found no difference between the two groups in terms of faecal calcium and magnesium content $(\mathrm{H}$. Bond, unpublished observations), suggesting that the intestinal handling of the ions is unaffected.

Irrespective of the mechanisms involved, the in-utero effects of maternal diabetes on mineral handling by kidney and bone, which extend to adulthood, may be of profound importance. The strength of a bone is determined by its size, shape and distribution of bone tissue. Thus, if the human adult offspring of diabetic individuals have generalised changes in cortical or trabecular bone mass similar to those seen in the long bones of the rats in this study, then their risk of bone fractures will be altered compared with that in the offspring of normal mothers. Similarly, there may be long-term implications for renal function in adults whose mothers were diabetic. Indeed, we have recently reported the results of a preliminary study showing decreased urinary calcium and magnesium excretion by children born to mothers with type 1 diabetes [31].

Acknowledgements We are very grateful to the Sir Jules Thorn Charitable Trust (London, UK) for funding this project and to Z. Mughal, J. Adams and N. Ashton for helpful discussion.

\section{References}

1. Gluckman PD, Hanson MJ (2004) Living with the past: evolution, development, and patterns of disease. Science 305:17331736

2. Barker DJP, Hales CN, Fall CHD, Osmond C, Phipps K, Clark PMS (1993) Type II (non-insulin dependent) diabetes mellitus, hypertension and hyperlipidemia (syndrome X): relation to fetal growth. Diabetologia 36:62-67

3. Aerts L, Van Assche FA (1979) Is gestational diabetes an acquired condition? J Dev Physiol 1:219-225

4. Hoelmans K, Aerst L, Van Assche FA (1991) Evidence for an insulin resistance in the adult offspring of pregnant streptozotocin-diabetic rats. Diabetologia 34:81-85

5. Tsang RC, Kleinman LI, Sutherland JM, Light IJ (1972) Hypocalcaemia in infants of diabetic mothers. Studies in calcium, phosphorus and magnesium metabolism and parathormone responsiveness. J Pediatr 80:384-395

6. Mimouni F, Tsang RC, Hertzberg VS, Miodovnik M (1986) Polycythemia, hypomagnesemia and hypocalcemia in infants of diabetic mothers. Am J Dis Child 140:798-800

7. Mimouni F, Loughhead J, Miodovnik M, Khoury J, Tsang RC (1990) Early neonatal predictors of neonatal hypocalcemia in infants of diabetic mothers: an epidemiologic study. Am J Perinatol 7:203-206 
8. Mimouni F, Mimouni CP, Loughead JL, Tsang RC (1991) A case-control study of hypocalemia in high risk neonates: racial, but no seasonal differences. J Am Coll Nutr 10:196-199

9. Tsang RC, Strub R, Brown DR, Steichen J, Hartman C, Chen IW (1976) Hypomagnesemia in infants of diabetic mothers: perinatal studies. J Pediatr 89:115-119

10. Mimouni F, Steichen JJ, Tsang RC, Hertzberg V, Miodovnik M (1988) Decreased bone mineral content in infants of diabetic mothers. Am J Perinatol 5:339-343

11. Lapillone A, Guerin S, Braillon P, Claris O, Delmas PD, Salle BL (1997) Diabetes during pregnancy does not alter whole body mineral content in infants. J Clin Endocrinol Metab 82:3993-3997

12. Verhaeghe J, Bouillon R, Lissens W, Visser WJ, Van Assche FA (1988) Diabetes and low Ca-P diet have opposite effects on adult and fetal bone mineral metabolism. Am J Physiol 254: E496-E504

13. Verhaeghe J, Van Bree R, Van Herck E et al (1999) Pathogenesis of fetal hypomineralization in diabetic rats: evidence for delayed bone maturation. Pediatr Res 45:209-217

14. Mishima N, Sahara N, Shirakawa M, Ozawa H (2002) Effect of streptozotocin-induced diabetes mellitus on alveolar bone deposition in the rat. Arch Oral Biol 47:843-849

15. Braddock R, Siman CM, Hamilton K, Garland HO, Sibley CP (2002) Gamma-linoleic acid and ascorbate improves skeletal ossification in offspring of diabetic rats. Pediatr Res 51:647652

16. Birdsey TJ, Husain SM, Garland HO, Sibley CP (1995) The effect of diabetes mellitus on urinary calcium excretion in pregnant rats and their offspring. J Endocrinol 145:11-18

17. Sharegi GR, Stoner LC (1986) Calcium transport across segments of the rabbit distal nephron in vitro. Am J Physiol 235: F367-F375

18. Hoenderop JG, van der Kemp AW, Hartog A et al (1999) Molecular identification of the apical calcium channel in 1,25dihydroxyvitamin D3-responsive epithelia. J Biol Chem 274: 8375-8378

19. Borke J, Caride A, Verma AK, Penniston JT, Kumar R (1989) Plasma membrane calcium pump and $28-\mathrm{kDa}$ calcium binding protein in cells of rat kidney distal tubules. Am J Physiol 257: F842-F849
20. Lehotsky J, Kaplan P, Murin R, Raeymaekers L (2002) The role of plasma membrane $\mathrm{Ca} 2+$ pumps (PMCAs) in pathologies of mammalian cells. Front Biosci 1:d53-d84

21. Hamilton K, Tein M, Glazier J et al (2000) Altered calbindin mRNA expression and calcium regulating hormones in rat diabetic pregnancy. J Endocrinol 164:67-76

22. Kavlock RJ, Gray JA (1982) Evaluation of renal function in neonatal rats. Biol Neonate 41:279-288

23. Parfitt AM, Drezner MK, Glorieux FH (1987) Bone histomorphometry: standardization of nomenclature, symbols, and units. Report of the ASBMR Histomorphometry Nomenclature Committee. J Bone Miner Res 6:595-610

24. Verhaeghe J, Bouillon R, Nyomba BL, Lissens W, Van Assche F (1986) Vitamin D and bone mineral homeostasis during pregnancy in the diabetic BB rat. Endocrinology 118:10191025

25. Garland HO, Harris PJ, Morgan TO (1991) Calcium transport in the proximal convoluted tubule and loop of Henle of rats made diabetic with streptozotocin. J Endocrinol 131:373-380

26. Bronner F, Stein WD (1988) CaBP facilitates intracellular diffusion for calcium pumping in distal convoluted tubule. Am J Physiol 255:F558-F562

27. Bond H, Sibley CP, Balment RJ, Ashton N (2003) Altered renal calcium handling by the offspring of diabetic rats. J Physiol 552P:P110

28. Holemans K, Van Bree R, Verhaeghe J, Meurrens K, Van Assche FA (1997) Maternal semistarvation and streptozotocindiabetes in rats have different effects on the in vivo glucose uptake by peripheral tissues in their female adult offspring. J Nutr 127:1371-1376

29. Husain SM, Birdsey TJ, Glazier JD, Mughal MZ, Garland HO, Sibley CP (1994) Effect of diabetes mellitus on maternofetal flux of calcium and magnesium and calbindin ${ }_{9 \mathrm{~K}}$ mRNA expression in rat placenta. Pediatr Res 35:376-381

30. Bond H, Sibley CP, Balment RJ, Ashton N (2005) Increased renal tubular reabsorption of calcium and magnesium by the offspring of diabetic rat pregnancy. Pediatr Res (in press)

31. Mughal MZ, Eelloo JA, Roberts S et al (2003) Intrauterine programming of urinary calcium and magnesium excretion in children born to mothers with insulin-dependent diabetes mellitus. Arch Dis Child (in press) 